\title{
Prevalence and Patterns of Psychosocial Problems among Adolescents with Epilepsy in Enugu, Nigeria: A Cross-Sectional Study
}

\author{
Chukwubike Onyebuchi Nnajekwu, MBBS, FMC Paed ${ }^{1 *}$, Uchenna Chiagoziem Nnajekwu, \\ MBBS, FMC Paed ${ }^{1}$, Anthony Nnaemeka Ikefuna, MBBS, FMC Paed, FRCP $P^{1,2}$ and Ngozi \\ Chinyelu Ojinnaka, MBBS, FWACP, MPH ${ }^{1,2}$
}

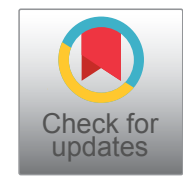

${ }^{1}$ Department of Paediatrics, Teaching Hospital, University of Nigeria, Nigeria

${ }^{2}$ Department of Paediatrics, College of Medicine, University of Nigeria, Nigeria

\begin{abstract}
Aim: To determine the prevalence and pattern of psychosocial problems in adolescents with epilepsy attending the neurology clinic of University of Nigeria Teaching Hospital (UNTH), Enugu.

Methods: This study was cross-sectional and hospital-based. One hundred and forty-five adolescents with epilepsy were recruited over nine months. Apparently healthy adolescents who were their classmates and matched for age and gender served as controls. The Paediatric Symptom Checklist -youth report version (PSC-YR) was used to assess psychosocial problems.

Results: The prevalence of psychosocial problems was significantly higher in the adolescents with epilepsy compared to the apparently healthy controls. Externalising problems were the most common pattern observed. No significant difference was found in the pattern of psychosocial problems between adolescents with epilepsy and apparently healthy controls. There was a significant relationship between psychosocial problems and either age, predominant seizure type or seizure frequency in the past 12 months among the adolescents with epilepsy and no significant relationship between psychosocial problems and either gender, social class, or number of antiepileptic drugs.
\end{abstract}

Interpretation: The prevalence of psychosocial problems among adolescents with epilepsy was significantly higher than that of apparently healthy controls. Also, these problems were influenced by either seizure frequency in the past 12 months or predominant seizure type but not number of antiepileptic drugs.

\section{Keywords}

Prevalence of behavioural problems, Prevalence of psychosocial problems, Adolescents with epilepsy

\section{Introduction}

Epilepsy is associated with significant psychosocial consequences [1,2]. The prevalence of psychopathology is four times higher in adolescents with epilepsy than in apparently healthy controls or adolescents with other chronic illnesses [3]. The unpredictability of the seizures, frequent hospital visits (from long term follow up), perceived stigmatization, regular interruption in academic activities and financial burden on affected families are the key factors implicated in these psychosocial problems, especially in adolescents [4].

The prevalence of psychosocial problems in children and adolescents with epilepsy varies according to location and study tools used. Freilinger, et al. [5] in Austria found a prevalence of moderate to severe psychosocial problems of $22.2 \%$ in 108 children and adolescents aged 5-18-years with various epilepsy syndromes, using the Child Behaviour Checklist (CBCL). Attention problems were the most common problems identified in the study. Aetiology, higher age at seizure onset and poly pharmacy were associated with higher CBCL scores. ${ }^{5}$ In Indonesia, Novriska, et al. [6] found a

*Corresponding author: Chukwubike Onyebuchi Nnajekwu, MBBS, FMC Paed, Department of Paediatrics, Teaching Hospital, University of Nigeria, Enugu, Nigeria, Tel: +2348037047182

Accepted: August 27, 2021

Published online: August 29, 2021

Citation: Nnajekwu CO, Nnajekwu UC, Ikefuna AN, et al. (2021) Prevalence and Patterns of Psychosocial Problems among Adolescents with Epilepsy in Enugu, Nigeria: A Cross-Sectional Study. J Pediatr Neurol Neurosci 5(2):155-163 
Citation: Nnajekwu CO, Nnajekwu UC, Ikefuna AN, et al. (2021) Prevalence and Patterns of Psychosocial Problems among Adolescents with Epilepsy in Enugu, Nigeria: A Cross-Sectional Study. J Pediatr Neurol Neurosci 5(2):155-163

prevalence of $19.1 \%$ in children and adolescents with epilepsy aged 3-16 years and $2.2 \%$ in children without epilepsy using the Strength and Difficulty Questionnaire (SDQ) Indonesian version. Factors associated with psychosocial problems were uncontrolled epilepsy and focal Electroencephalogram (EEG) findings [6]. Choudary, et al. [7] in India, found an overall prevalence of $44 \%$ in children with epilepsy aged 6-12-years (42\% in generalized seizures and $53.8 \%$ in partial seizures) and $9 \%$ in children without epilepsy using the Paediatric Symptom Checklist. Increased frequency of seizures and seizure type were significantly associated with psychosocial problems [7].

In Nigeria, the prevalence of psychosocial disorders in children and adolescents with epilepsy ranges from 30 to $90 \%$, while studies from the western world reported lower prevalence rates of 23 to $70.5 \%$ [3,8-13]. The prevalence of psychosocial problems is much lower in apparently healthy adolescents without epilepsy in Nigeria, ranging from 2 to $25 \%[3,10]$. Depression, anxiety disorders, conduct disorders and attention deficit hyperactivity disorder were among the most common problems reported in literature [3,8-10]. Risk factors implicated as predictors of psychosocial problems include; older age, female gender, uncontrolled seizures, longer duration of illness, poly therapy and stigma $[3,4,10]$.

In busy paediatric neurology clinics, time constraints may make physicians focus more on epilepsy control and neurologic assessment and overlook routine assessment of emotional state, and referrals to psychiatrists only occur when there is crisis or concern from teachers and family members [14]. Tools and structured questionnaires such as DISC IV, Rutter $A_{2}$ scale, HADS and K-SADS which offer accurate and detailed diagnoses have been used in studies in Africa to detect psychosocial problems, but these tools are lengthy and time consuming for use in a busy paediatric clinic $[3,8-10,15]$. The Paediatric symptom checklist (PSC) is a brief screening questionnaire designed for use in busy clinics to assist general paediatricians in identifying psychosocial problems in children [16].

The available studies conducted in Nigeria targeted specific symptom clusters, such as anxiety and depression, but the PSC is a tool that offers a much broader perspective of the psychosocial problems of children. Most of the available studies in Nigeria focused more on psychosocial problems in adolescents with epilepsy, without comparing them with apparently healthy adolescents [8-11]. Most of the tools used in the Nigerian studies used reports from parents or teachers $[3,10]$. Self-report instruments are particularly useful in diagnosing internalizing problems, as the care givers may not give an accurate report of the symptoms [17]. In addition, all of the studies in children and adolescents in Nigeria were conducted in the south-western and northern parts of Nigeria $[3,8,10,11]$. These people in these regions have diverse cultural beliefs and educational attainments which may adversely affect these adolescents in terms of their emotional well-being. To the best of the author's knowledge, no such study has been conducted in the south-eastern Nigeria.

This study therefore, aims to determine the prevalence and pattern of behavioural and emotional problems, the relationship between psychosocial problems and either socio- demographic factors (age, gender and social class) or seizure variables (type of seizure, number of anti-epileptic drugs, frequency of seizure in the past 12 months) in adolescents with epilepsy attending the neurology clinic of University of Nigeria Teaching Hospital (UNTH), Enugu. Findings from this study will add to the increasing knowledge on this challenging condition and aid in the management of adolescents with this disorder to improve their overall well-being.

\section{Methods}

This was a hospital based, cross-sectional study, carried out in the Paediatric Neurology clinic, UNTH, Enugu (southeastern Nigeria) over a 9-month period extending from March to December, 2016. Included in the study were adolescents aged 10-years to 18-years with epilepsy who have been on follow-up for at least one year at the Paediatric Neurology clinic, could read and write and are enrolled in school. These adolescents and their caregivers also gave assent/consent to participate in the study. Adolescents with epilepsy who had epilepsy syndromes, other neurologic or chronic conditions were excluded from the study. The classmates of the adolescents with epilepsy who were matched for age and gender were recruited as controls in their respective schools. These 'apparently healthy' controls did not have epilepsy or any other acute or chronic ailment.

Approval was obtained from the Ethical and Research Review Committee of UNTH Ituku- Ozalla before the commencement of the study. Thumb printed and/or signed informed consent forms were obtained from the parents or care givers. Information regarding the method of the study and the benefits were provided to the parents and care givers. Assent was also obtained from the adolescents with epilepsy. Confidentiality of all data obtained was ensured.

\section{Enrolment of adolescents with epilepsy}

Adolescents with epilepsy were recruited based on the clinical information obtained from their medical records which were in keeping with epilepsy. The adolescents who met the inclusion criteria had a written consent given to their parents or care givers and the adolescents gave their assent. Adolescents with epilepsy were enrolled consecutively on clinic days until the calculated sample size was reached.

On the day the schools were initially visited, a formal introduction of the researcher was made. Also, the letter of authorisation from the Enugu State Post-Primary School Management Board was presented to the School authorities. At this visit, information on the study design and objectives were provided by the researcher. After approval by the school authority was obtained, the class of the adolescents with epilepsy was identified and the first student on the class register that matched the adolescents with epilepsy for age and gender, and met the inclusion criteria was selected. Informed consent form and a proforma designed for the study were given to the students to take home to the parents or care givers. The parents or care givers were contacted with the telephone number provided on the proforma to verify all information provided. Adolescents in the control group were thus enrolled consecutively till the sample size was achieved. 
Citation: Nnajekwu CO, Nnajekwu UC, Ikefuna AN, et al. (2021) Prevalence and Patterns of Psychosocial Problems among Adolescents with Epilepsy in Enugu, Nigeria: A Cross-Sectional Study. J Pediatr Neurol Neurosci 5(2):155-163

\section{Study tools}

Information regarding age and gender of the adolescents, educational status and occupation of their care givers and the adolescents with epilepsy and control's clinical history were obtained by the investigator using an interviewer administered questionnaire designed for this study. Information regarding the presence of epilepsy and other neurological problems, chronic illnesses such as asthma, sickle cell anaemia, diabetes mellitus and human immunodeficiency virus infection were obtained from the parents of the controls using the interviewer administered proforma. The predominant seizure type was obtained from the EEG report in the patient's records, while the other seizure variables (number of anti-epileptic drugs and number of seizures in the past twelve months) were obtained from both the patient's records and interviewing the adolescents with epilepsy and their parents. Epilepsy was classified according to the 2017 International League Against Epilepsy (ILAE) classification. For the purpose of this study, adolescence was defined as children aged 10 to 18-years based on the recommendation by the World Health Organisation [18] (a period from 10 to 19-years of age). The socioeconomic status of the families of both the adolescents with epilepsy and the controls was determined using the social classification system by Oyedeji [19] using a two-factor index of parental occupation and educational attainment for scoring. Each of the factors used in the classification was graded 1 to 5 with class one being the highest social class and class five, the lowest. The mean score for both parents to the nearest whole number is the social class assigned to the child. Where any of the parents is dead, the social class assigned to the child was determined by that of the living parent or guardian only. For the purposes of this study, classes one and two of the Oyedeji classification represented the upper social class, class three represented the middle social class, and classes four and five represented the lower social class.

The psychosocial problems of the adolescents with epilepsy and controls were assessed using the English version of a thirty-five item self-administered Paediatric Symptom Checklist Youth report version (PSC-YR) [13]. It consists of three subscales; the attention subscale which consists of five items (numbers $4,7,8,9,14$ ), internalising subscale which contains five items $(11,13,19,22,27)$, and the externalising subscale which consists of seven items $(16,29,31,32,33$, $34,35)[16,19,20]$. A cumulative score of twenty eight on the PSC indicates the presence of psychosocial problems [16-21]. Also, a score of seven on the externalisation subscale, and five on the attention and internalisation subscales indicate the pattern of psychosocial problems present $[16,19,20]$. The patterns of psychosocial problems were classified into: Attention, externalizing, and internalising problems [16].

Validity studies have shown that PSC case definition correlates with $\mathrm{CBCL}$ of Achenbach and Edelbrock, with an acceptable Kappa of 0.52 and Cronbach alpha of 0.86 $[15,21,22]$. The PSC has been validated for use in general paediatric screening as well as in subspecialty clinics [23] and surveys in Nigeria using a cut-off of $\geq 28$ [21,23-25].
Adequate test-retest reliability and interval consistency with a specificity of $68 \%$ and sensitivity of $95 \%$ was reported in a study [26]. For the purpose of this study, positive score or positive for psychosocial problems indicates a PSC score $\geq 28$, while negative score or negative for psychosocial problems indicates a PSC score $<28$.

The adolescents who were screened to have psychosocial problems were counselled, further assessed and in some cases referred to the Psychiatrists for further evaluation and management. Adolescents were classified into early (10 to 13 -years), mid (14 to 16 -years) and late adolescence (17 to 19-years).

\section{Data analysis}

This was done using Statistical Package for Social Sciences (SPSS) version 19.0. Frequency tables were generated for socio-demographic variables. Descriptive statistics were used to summarise quantitative variables while qualitative variables were summarised using proportions. The Chi-square test was used to determine the distribution of psychosocial problems in the different socio-demographic variables of the study population. Logistic regression was used to test for significant association between socio-demographic, seizure variables and psychosocial problems. Results were presented in prose and tables. All analyses were done at the $5 \%$ level of significance and a $p$-value less than 0.05 was considered statistically significant.

\section{Results}

A total of 155 adolescents aged 10 to18-years took part in the 9-month study. Ten were excluded from the study because they did not fill their questionnaires properly. Thus, 145 (82 males and 63 females) were finally screened for behavioural and emotional problems, giving a completion rate of $93.54 \%$. One hundred and forty five adolescents without epilepsy, matched for age and gender with adolescents with epilepsy, served as controls.

\section{Socio-demographic characteristics of adoles- cents with epilepsy and controls and distribution of adolescents with epilepsy based on seizure variables}

The adolescents with epilepsy were made up of 82 males and 63 females, with a male: female ratio of (1.3:1). Most of the adolescents with epilepsy and controls were early adolescents. The controls were similarly distributed for age and gender. Majority of the adolescents with epilepsy and controls (69\% and $90 \%$ respectively) belonged to the upper social class. The difference between the social classes of the adolescents with epilepsy and controls was statistically significant $(p=0.015)$.

The most common predominant type of epilepsy was the generalized tonic-clonic epilepsy (44.8\%). Majority of the adolescents with epilepsy (55.2\%) had 1-12 seizures in the past twelve months, while most of the adolescents with epilepsy $(72.4 \%)$ were receiving more than one anti-epileptic drug as seen in Table 1. 
Citation: Nnajekwu CO, Nnajekwu UC, Ikefuna AN, et al. (2021) Prevalence and Patterns of Psychosocial Problems among Adolescents with Epilepsy in Enugu, Nigeria: A Cross-Sectional Study. J Pediatr Neurol Neurosci 5(2):155-163

Table 1: Socio-Demographic characteristics of the study participants and distribution of adolescents with epilepsy based on seizure variables.

\begin{tabular}{|c|c|c|c|c|}
\hline & $\begin{array}{l}\text { Adolescents with } \\
\text { epilepsy n (\%) }\end{array}$ & $\begin{array}{l}\text { Controls } \\
\text { n (\%) }\end{array}$ & Chi square & $p$ value \\
\hline Gender & & & 0 & 1 \\
\hline Male & $82(56.6)$ & $82(56.6)$ & & \\
\hline Female & $63(43.4)$ & $63(43.4)$ & & \\
\hline Total & $145(100.0)$ & $145(100.0)$ & & \\
\hline Age groups & & & 0 & 1 \\
\hline Early adolescent & $61(42.1)$ & $61(42.1)$ & & \\
\hline Mid adolescent & 57 (39.3) & $57(39.3)$ & & \\
\hline Late adolescent & $27(18.6)$ & $27(18.6)$ & & \\
\hline Total & $145(100.0)$ & $145(100.0)$ & & \\
\hline Socio-economic class & & & 8.415 & $0.015^{*}$ \\
\hline Lower & $29(20.0)$ & $14(9.7)$ & & \\
\hline Middle & $47(32.4)$ & $41(28.3)$ & & \\
\hline Upper & $69(47.6)$ & $90(62.1)$ & & \\
\hline Total & $145(100.0)$ & $145(100.0)$ & & \\
\hline \multicolumn{5}{|c|}{ Seizure variables of adolescents with epilepsy } \\
\hline \multicolumn{5}{|l|}{ Seizure type } \\
\hline Generalized tonic clonic & $65(44.8)$ & & & \\
\hline Atonic & $15(10.3)$ & & & \\
\hline Absence & $16(11.0)$ & & & \\
\hline Focal impaired awareness & $31(21.4)$ & & & \\
\hline Focal to bilateral tonic clonic & $15(10.3)$ & & & \\
\hline Focal aware & $3(2.1)$ & & & \\
\hline Total & $145(100.0)$ & & & \\
\hline \multicolumn{5}{|c|}{ Seizure frequency in the past 12 months } \\
\hline None & $48(33.1)$ & & & \\
\hline 01-Dec & $80(55.2)$ & & & \\
\hline$>12$ & $17(11.7)$ & & & \\
\hline Total & $145(100.0)$ & & & \\
\hline \multicolumn{5}{|c|}{ Number of anti-epileptic medications used in treatment } \\
\hline 1 & $105(72.4)$ & & & \\
\hline$>1$ & $40(27.6)$ & & & \\
\hline Total & $145(100.0)$ & & & \\
\hline
\end{tabular}

*Statistically significant at $p<0.05$

Prevalence and patterns of psychosocial problems in the study population using the PSC

Table 2 describes the prevalence and patterns of psychosocial problems in adolescents with and without epilepsy using the PSC. The difference in the proportion of the adolescents with epilepsy and control with PSC scores in the psychosocial problem range ( $P S C \geq 28$ ) was significant $(p<0.001$, or $7.772,95 \%$ C.I $3.352-18.020)$. Adolescents with epilepsy were 8 times more likely to have psychosocial problems than adolescents without epilepsy.
Externalising problems were the most common pattern of psychosocial problem in the adolescents with epilepsy and controls. None of the adolescents with epilepsy or controls tested positive on more than one subscale. There was no significant difference demonstrated in the pattern of psychosocial problems between the adolescents with epilepsy and controls. (Fisher's exact significance $=1.000$ ).

\section{Relationship between socio-demographic variables and psychosocial problems in the adolescents with epilepsy}


Citation: Nnajekwu CO, Nnajekwu UC, Ikefuna AN, et al. (2021) Prevalence and Patterns of Psychosocial Problems among Adolescents with Epilepsy in Enugu, Nigeria: A Cross-Sectional Study. J Pediatr Neurol Neurosci 5(2):155-163

Table 2: Prevalence and pattern of psychosocial problems in the study participants.

\begin{tabular}{|c|c|c|c|c|c|}
\hline Variable & $\begin{array}{l}\text { Adolescents with epilepsy } \\
\mathrm{n}(\%)\end{array}$ & $\begin{array}{l}\text { Controls } \\
\text { n (\%) }\end{array}$ & p value & OR & 95\% C.I for OR \\
\hline \multicolumn{6}{|c|}{ Prevalence of psychosocial problems } \\
\hline Positive score & $41(28.3)$ & $7(4.8)$ & $<0.001^{*}$ & 7.772 & $3.352-18.020$ \\
\hline Negative score & $104(71.7)$ & $138(95.2)$ & & & \\
\hline Total & $145(100.0)$ & $145(100.0)$ & & & \\
\hline \multicolumn{6}{|c|}{ Pattern of psychosocial problems } \\
\hline Attention problems & $11(26.8)$ & $2(28.6)$ & $1.000^{\mathrm{a}}$ & & \\
\hline Internalising problems & $14(34.2)$ & $2(28.6)$ & & & \\
\hline Externalising problems & $16(39.0)$ & $3(42.8)$ & & & \\
\hline Total & $41(100.0)$ & $7(100.0)$ & & & \\
\hline
\end{tabular}

*Statistically significant at $\mathrm{p}<0.05$

Negative score: $\mathrm{PSC}<28$, positive score: PSC $\geq 28$, aFisher's exact test.

Table 3: Relationship between socio-demographic variables and psychosocial problems in the study participants.

\begin{tabular}{|c|c|c|c|c|c|c|}
\hline \multirow[t]{2}{*}{ Socio-demographic variables } & \multicolumn{3}{|c|}{$\begin{array}{l}\text { Participants with psychosocial problems } n(\%) \\
(n=48)\end{array}$} & \multicolumn{3}{|c|}{$\begin{array}{l}\text { psychosocial status of adolescents with epilepsy } \\
n(\%)(n=145)\end{array}$} \\
\hline & Control & $\begin{array}{l}\text { Adolescents with } \\
\text { epilepsy }\end{array}$ & $\begin{array}{l}\text { Chi-Square } \\
\text { (p-value) }\end{array}$ & Negative & Positive & $\begin{array}{l}\text { Wald } \\
\text { (p- value) }\end{array}$ \\
\hline \multicolumn{3}{|l|}{ Age Group } & \multirow[t]{5}{*}{$3.847(0.163)$} & & & \multirow[t]{5}{*}{$9.80(0.002)^{*}$} \\
\hline Early adolescence & $0(0.0)$ & $12(29.3)$ & & $49(47.1)$ & $12(29.3)$ & \\
\hline Mid adolescence & $5(71.4)$ & $15(36.6)$ & & $42(40.4)$ & $15(36.6)$ & \\
\hline Late adolescence & $2(28.6)$ & $14(34.1)$ & & $13(12.5)$ & $14(34.1)$ & \\
\hline Total & $7(100)$ & $41(100)$ & & $104(100.0)$ & $41(100.0)$ & \\
\hline \multicolumn{3}{|l|}{ Gender } & \multirow[t]{4}{*}{$1.505(0.416)$} & & & \multirow[t]{4}{*}{$1.51(0.219)$} \\
\hline Male & $2(28.6)$ & $22(53.7)$ & & $60(57.7)$ & $22(53.7)$ & \\
\hline Female & $5(71.4)$ & $19(46.3)$ & & $44(42.3)$ & $19(46.3)$ & \\
\hline Total & $7(100.0)$ & $41(100.0)$ & & $104(100.0)$ & $41(100.0)$ & \\
\hline \multicolumn{3}{|l|}{ Socio-economic class } & \multirow[t]{5}{*}{$2.171(0.439)$} & & & \multirow[t]{5}{*}{$1.68(0.194)$} \\
\hline Upper & $4(57.1)$ & $17(41.5)$ & & $52(50.0)$ & $17(41.5)$ & \\
\hline Mid & $3(42.9)$ & $14(34.1)$ & & $33(31.7)$ & $14(34.1)$ & \\
\hline Lower & $0(0.0)$ & $10(24.4)$ & & $19(18.3)$ & $10(24.4)$ & \\
\hline Total & $7(100.0)$ & $41(100.0)$ & & $104(100.0)$ & $41(100.0)$ & \\
\hline
\end{tabular}

*Statistically significant at $p<0.05$, positive for psychosocial problems: PSC $\geq 28$

The highest prevalence of psychosocial problems was noted in the mid adolescent age group amongst adolescents with epilepsy (36.6\%) and controls (71.4\%). Psychosocial problems were more common in the male adolescents with epilepsy and female controls. The highest prevalence of psychosocial problems in the adolescents with epilepsy and controls was noted in the upper socioeconomic class. The difference in prevalence of psychosocial problems in amongst the various socio-demographic variables of the adolescents with epilepsy and control were not significant $(p=0.163$, $0.416,0.439)$.

There was a significant relationship between age and psychosocial problems among the adolescents with epilepsy $(p=0.002)$. However, there was no significant relationship between psychosocial problems and either gender or socioeconomic class as seen in Table 3.

\section{Relationship between seizure variables and psychosocial problems}

Table 4 shows the relationship between seizure variables (predominant seizure type, seizure frequency, and number of anti-epileptic drugs) and psychosocial problems. There was a significant relationship between psychosocial problems and both predominant seizure type and number of seizures in the past year ( $p=0.010$ and 0.026 respectively). However, there was no significant relationship between psychosocial problems and number of anti-epileptic drugs used. 
Citation: Nnajekwu CO, Nnajekwu UC, Ikefuna AN, et al. (2021) Prevalence and Patterns of Psychosocial Problems among Adolescents with Epilepsy in Enugu, Nigeria: A Cross-Sectional Study. J Pediatr Neurol Neurosci 5(2):155-163

Table 4: Relationship between seizure variables and psychosocial problems.

\begin{tabular}{|c|c|c|c|}
\hline \multirow[t]{2}{*}{ Seizure Variables } & \multicolumn{2}{|c|}{ Psychosocial problems } & \multirow[t]{2}{*}{ Wald (p-value) } \\
\hline & Negative $\mathrm{n}(\%)$ & Positive n (\%) & \\
\hline \multicolumn{4}{|l|}{ Predominant Seizure Type } \\
\hline Generalised Tonic Clonic & $46(44.2)$ & $19(46.3)$ & \multirow[b]{6}{*}{$15.044(0.010)^{*}$} \\
\hline Atonic & $9(8.7)$ & $6(14.6)$ & \\
\hline Absence & $12(11.5)$ & $4(9.8)$ & \\
\hline Focal impaired awareness (complex partial) & $28(26.9)$ & $3(7.3)$ & \\
\hline Focal to bilateral Tonic Clonic (Partial with secondary generalisation) & $6(5.8)$ & $9(22.0)$ & \\
\hline Focal Aware (simple partial) & $3(2.9)$ & $0(0.0)$ & \\
\hline Total & $104(100.0)$ & $41(100)$ & \\
\hline \multicolumn{4}{|l|}{ Number of Seizures in the past one year } \\
\hline None & $40(38.5)$ & $8(19.5)$ & \multirow[b]{4}{*}{$4.93(0.026)^{*}$} \\
\hline 01-Dec & $53(51.0)$ & 27 (65.9) & \\
\hline Greater than 12 & $11(10.6)$ & $6(14.6)$ & \\
\hline Total & $104(100.0)$ & $41(100)$ & \\
\hline \multicolumn{4}{|l|}{ Number of AEDs } \\
\hline One & $80(76.9)$ & $25(61.0)$ & \multirow[b]{3}{*}{$3.744(0.064)$} \\
\hline More than 1 & $24(23.1)$ & $16(39.0)$ & \\
\hline Total & $104(100)$ & $41(100)$ & \\
\hline
\end{tabular}

*Statistically significant at $\mathrm{p}<0.05$; Negative for psychosocial problems: PSC $<28$; Positive psychosocial problems: PSC $\geq 28$

\section{Discussion}

The present study highlights the prevalence, patterns, and determinants of psychosocial problems in adolescents with epilepsy (an under-reported population), when compared with apparently healthy controls. This was conducted using a screening tool, the PSC, which is a self-reporting instrument that gives an accurate report of how the child feels, without relying on information from parents and teachers. This is particularly important in the diagnosis of internalizing problems which may not be obvious to the parents or teachers. The PSC merely identifies patients who would need further assessment, but does not identify specific diagnoses, unlike some of the studies cited $[3,8-10,12,27]$ which targeted specific symptom clusters with measures that are based on DSM criteria.

Findings from this study show that about one-third of the adolescents with epilepsy had psychosocial problems. This could worsen their morbidity and treatment outcomes. Hence, there is need for psychological services in adolescents with epilepsy to improve their overall state of health. Higher prevalence rates were reported by Davies, et al. [12] in Britain, Heddrick and Buchhalter [27] in Rochester, Choudhary, et al. [7] in India, Adewuya, et al. [3] in Ife and Lagunju and colleagues [10] in Ibadan, Nigeria. The differences in methodology and assessment tools used could explain the lower prevalence rates documented in this study. This study and that of Choudhary, et al. [7] used a self-administered tool, PSC while parents or teachers of the adolescents with epilepsy completed the forms for the adolescents with epilepsy in the other studies. In addition, this study excluded adolescents with epilepsy who had other neurological conditions, unlike the other studies. These may have accounted for the lower prevalence of psychosocial problems observed in this study.

The adolescents with epilepsy in this study had a significantly higher prevalence of psychosocial problems than the controls. This was similar to findings from other studies $[7,10,11]$. The high rate of psychosocial problems among adolescents with epilepsy may be due to the stress of having a chronic illness, in this case, epilepsy, acting as a significant risk factor. Stress associated with diagnosis, on-going stress of treatment, social disruption, stigma, marginalisation and changes in plans for the future can be a challenge to social and emotional wellbeing. It has been propounded that chronic stress leads to overproduction of interleukin 6 , a pro-inflammatory cytokine associated with a spectrum of disorders including depression [28]. The unpredictability of the seizures, frequent hospital visits (from long term follow up), perceived stigmatization, regular interruption in academic activities and financial burden on affected families could also explain the higher prevalence observed in adolescents with epilepsy [4].

Considering the pattern of psychosocial problems in adolescents with epilepsy, the study reported a higher prevalence of externalizing symptoms. The reason for the increased prevalence of externalizing and attention problems in adolescents with epilepsy is not clear, but may be due to the AED used in treatment, as drugs like phenobarbitone, levetiracetam, sodium valproate et cetera have been linked with increased risk of externalizing and attention problems [29]. There is paucity of research on patterns of psychosocial 
Citation: Nnajekwu CO, Nnajekwu UC, Ikefuna AN, et al. (2021) Prevalence and Patterns of Psychosocial Problems among Adolescents with Epilepsy in Enugu, Nigeria: A Cross-Sectional Study. J Pediatr Neurol Neurosci 5(2):155-163

problems in children and adolescents with epilepsy using the PSC. There are conflicting reports on patterns of psychosocial problems in literature. The rate for internalising symptoms (anxiety and depressive symptoms) reported in this study was similar to the rates reported by Novriska, et al. [6] and Adewuya, et al. [3] but higher than the rate reported by Lagunju and colleagues [10]. The rate for externalising symptoms from this study was higher than that reported by Caplan, et al. [30] in USA, Novriska, et al. [6] in Indonesia, and Lagunju, et al. [10] in Nigeria. The prevalence rate for attention problems in this study was similar to the report of Lagunju, et al. [10] but higher than the report of Novriska and colleagues [6]. The difference in findings for the patterns of psychosocial problems may be due to cultural factors and methodology of the studies reported. The different study tools and interpretation may have accounted for the different findings observed. This study was on adolescents aged 10-years to 18-years using the PSC, Caplan, et al. [30] studied children aged between 5-years and 16-years with complex partial seizures using the $\mathrm{CBCL}$, Novriska, et al. [6] studied children aged 3 to 16-years using the Indonesian version of the SDQ, while Lagunju, et al. [10] studied children aged 5 to 18 years using the Rutter $A_{2}$ scale.

A significant relationship was established between age and psychosocial problems among the adolescents with epilepsy in this study. Psychosocial problems were most common in the mid adolescent age group and lowest in the late adolescents. The significant relationship with age was similar to the findings of Karanja in Kenya [31], but different from that of Novriska, et al. [6] in Indonesia who found no relationship between age and psychosocial problems. The significant relationship is not surprising since adolescents become more aware of themselves as they grow older and are more likely to have psychosocial problems than younger children. The trend of psychosocial problems being highest in mid-adolescence in our study may be because as adolescents grow from early to mid to late adolescence, they grapple with self-identity and maturity which they begin to come to terms with by late adolescence. This further emphasizes the need for prompt institution of mental health support systems as early as possible to reduce effects of these psychosocial problems as these adolescents grow older. Gender and socio-economic class were not significantly related to psychosocial problems. This study corroborates others $[6,32,33]$ in this regard. The finding of no relationship between socioeconomic class and psychosocial problems is not unexpected. The reason for the lack of relationship between gender and psychosocial problems is not clear.

There was a significant relationship between seizure type and psychosocial problems in this study. Psychosocial problems were more common in adolescents with generalised tonic clonic seizures. This finding is similar to the report by Hoie, et al. [13] in Norway, but differs from the report of Adewuya and colleagues [3] in Western Nigeria and Nur, et al. [34] in Indonesia who found no relationship between seizure type and psychosocial problems. This present study classified epilepsy into several subtypes using the 2017 ILAE classification while Nur, et al. [34] and Adewuya and colleagues [3] grouped seizures as generalised and partial and could account for the differences observed. Previous studies have shown that psychosocial problems are more common in people with focal seizures (temporal lobe epilepsy) due to the location of the hippocampus in the temporal lobe, making it prone to insult from repeated seizures and chronic stress $[7,30,35]$. Findings from this study deviated from the norm. The higher prevalence in people with generalised tonic seizures may have occurred because these seizures have manifestations that are obvious, and if the seizures occur in public, it could lead to stigmatisation, low self-esteem and psychosocial problems [36].

There was no significant relationship found between the number of AEDs used and psychosocial problems in adolescents with epilepsy. Poly therapy has been shown to be a significant risk factor for psychosocial problems because the patients feel their illness is more severe than others, leading to excessive worry, stress and anxiety $[3,30,37]$. The findings from this study were similar to the findings of Helal, et al. [38] and Nur, et al. [34] who documented no significant difference in scores on psychotic symptoms, attention problems and motor excess scales between adolescents with epilepsy on mono therapy, poly therapy and control. On the other hand, several other studies $[3,30,37]$ showed that poly therapy with AEDs was a significant predictor of psychosocial problems. The differences noted could be due to the different study tools used. This study used a screening tool, which does not give specific diagnoses unlike the diagnostic tools used in the other studies.

A significant relationship was found between seizure frequency and psychosocial problems in this study. People with frequent seizures feel their illness is more severe than others, and have concerns for the future. This could increase the risk of psychosocial problems. The findings from this study corroborate findings from other authors $[3,7,11,30,37,39]$. Caplan and colleagues [30] in the USA, and Nur, et al. [34] on the other hand, reported no significant relationship between psychosocial problems and seizure frequency in children with epilepsy. It is noted that depression and anxiety, for instance, are significantly associated with frequency of seizure before commencement of therapy [40]. This is not surprising since epilepsy is highly stigmatised and this worsens if the attack occurs in the public [36]. The felt stigma and shame can predispose adolescents with this disorder to emotional instability and low self-esteem with subsequent psychosocial problems and this situation often worsens with increased number of attacks $[31,39,40]$. Cultural differences with different beliefs may be responsible for the varying reports by the authors.

The study is not without limitations; the study tool used was a screening tool, which does not give specific diagnoses. Information regarding the health status of the apparently healthy adolescents was obtained from the parents, and this could constitute a bias, as the parents may not have given accurate reports. Also, some of the apparently healthy controls might have had some subtle chronic health conditions or neurological conditions that were not obvious to their parents or guardians. The adolescents who were 
Citation: Nnajekwu CO, Nnajekwu UC, Ikefuna AN, et al. (2021) Prevalence and Patterns of Psychosocial Problems among Adolescents with Epilepsy in Enugu, Nigeria: A Cross-Sectional Study. J Pediatr Neurol Neurosci 5(2):155-163

recruited were those who could read and write, but some of these adolescents could have had borderline intellectual disabilities which could have affected the scores obtained from the study tool. Only adolescents with epilepsy attending the neurology clinic were studied. Generalization beyond this sample population may require replication of the study in 'out of hospital' and community adolescents. In addition, this is a cross sectional study and thus, may not establish a causeand-effect relationship. Case-controlled, longitudinal studies are needed.

The authors recommend evaluation of any identified adolescent with epilepsy for psychosocial problems, and counselling or referral for treatment at a specialist clinic. Mental health services should be integrated into already existing clinical services for a more comprehensive and effective health care delivery to this group of children. Thus, a clinical psychologist and a mental health physician should be attached to the Paediatric neurology clinics to help provide continuous mental health care to children and adolescents with epilepsy.

\section{Declarations}

\section{Ethical approval and consent to participate}

Ethical consent was obtained from the Health Research and Ethics Committee of University of Nigeria Teaching Hospital, Enugu. (Approval number NHREC/05/01/2008BFWA00002458-IRB00002323) Consent was obtained from the parents and care-givers of the study adolescents with epilepsy. Assent was obtained from the study adolescents with epilepsy.

\section{Consent for publication}

Not applicable.

\section{Availability of data and materials}

The datasets used and/or analysed during the current study are available from the corresponding author on reasonable request.

\section{Declaration of interest}

The authors have stated that they had no interests which might be perceived as posing a conflict or bias.

\section{Funding}

The research did not receive any specific grant from funding agencies in the public, commercial, or not-for-profit sectors.

\section{Authors contributions}

CO and UC were involved in the conception of the work, acquisition, analysis, interpretation of data, and drafted and edited the submitted version of the manuscript.

NC, NA were involved in the conception of the work, acquisition, analysis, interpretation of data, and substantively revised and approved the submitted version of the manuscript.

All authors agreed to be personally accountable for their contributions and to ensure that questions related to the accuracy or integrity of any part of the work are appropriately investigated, resolved, and the resolution documented in literature.

\section{Acknowledgements}

None.

\section{References}

1. Ong LC (2013) Anxiety and depression in children with epilepsy. Neurol Asia 18: 39-41.

2. Baker GA, Spector S, Mc Grath Y, et al. (2005) Impact of epilepsy in adolescence: A UK controlled study. Epilepsy Behav 6: 556562.

3. Adewuya AO, Ola BA, Okeniyi JAO (2005) Psychiatric morbidity in Nigerian adolescents with epilepsy. J Paediatr Neurol 3: 153-158.

4. Macleod JS, Austin JK (2003) Stigma in the lives of adolescents with epilepsy: A review of the literature. Epilepsy Behav 4: 112117.

5. Freilinger M, Reisel B, Reiter E, et al. (2006) Behavioural and emotional problems in children with epilepsy. J Child Neurol 21: 939-945.

6. Novriska D, Sutomo R, Setyati A (2014) Behavioural problems in children with epilepsy. Paediatr Indones 54: 324-329.

7. Choudhary S, Niranjan N, Khichar S, et al. (2017) Behavioural problems and intelligence quotient changes in pediatric epilepsy: A case-control study. J Neurosci Rural Pract 8: 617-621.

8. Fela-Thomas A, Akinhanmi AA, Esan O (2016) Prevalence and correlates of major depressive disorder among adolescent patients with epilepsy attending a Nigerian neuropsychiatric hospital. Epilepsy Behav 54: 58-64.

9. Nuhu FT, Yusuf AJ, Lasisi MD, et al. (2013) Emotional distress among people with epilepsy in Kaduna, Northern Nigeria. Ann Trop Med PH 6: 42-46.

10. Lagunju IA, Bella-Awurah TT, Takon I, et al. (2012) Mental health problems in Nigerian children with epilepsy: associations and risk factors. Epilepsy Behav 25: 214-218.

11. Ogun OC, Gbiri CA, Akinola OE, et al. (2012) Psychosocial correlates of depression in children and adolescents with epilepsy in a Nigerian neuropsychiatric hospital. J Clin Case Rep 2: 152.

12. Davies S, Heyman I, Goodman R (2003) A population survey of mental health problems in children with epilepsy. Dev Med Child Neurol 45: 292-295.

13. Hoie B, Sommerfelt K, Alasker FD, et al. (2008) The combined burden of cognitive, executive function and psychosocial problems in children with epilepsy: A population-based study. Dev Med Child Neurol 50: 530-536.

14. Anderson DL, Spratt EG, Macias MM, et al. (1999) Use of the pediatric symptom checklist in the pediatric neurology population. J Pediatr Neurol 20: 116-120.

15. Bioh R, Durowaa R, Kumasenu B, et al. (2018) Cognitive and psychosocial deficits in children with epilepsy at the Korle-Bu Teaching Hospital in Ghana. INDJ 12: 1-9.

16. http://www.dbpeds.org/handouts

17. Youngstrom EA, Prinstein MJ, Mash EJ (2020) Assessment of 
Citation: Nnajekwu CO, Nnajekwu UC, Ikefuna AN, et al. (2021) Prevalence and Patterns of Psychosocial Problems among Adolescents with Epilepsy in Enugu, Nigeria: A Cross-Sectional Study. J Pediatr Neurol Neurosci 5(2):155-163

childhood disorders. In: Barkley RA ( $5^{\text {th }}$ edn), Guilford Press, New York, 730.

18. https://apps.who.int/adolescent/second-decade/section2/ page1/recognizing-adolescence.html

19. Oyedeji GA (1985) Socioeconomic and cultural health background of hospitalised children in llesha. Niger J Paediatr 12: 111-117.

20. Stoppelbein L, Greening L, Jordan SS, et al. (2005) Factor analysis of the Paediatric Symptom Checklist with a chronically ill pediatric population. J Dev Behav Pediatr 26: 349-355.

21. Akenzua GI (1990) Screening for psychosocial dysfunction in children with sickle cell anaemia. Nig J Paediatr 17: 15-21.

22. Achenbach TM, Edelbrock CS (1983) Manual for the child behaviour checklist and revised child behaviour profile. VT: Queen city Printers, Burlington.

23. Taiwo AO (2011) Predictors of psychopathology among Nigerian adolescents: The role of psychosocial, demographics, personality and medical condition reports domains. Afr Health Sci 11: 228239.

24. Anyanwu OU, Ibekwe RC, Ojinnaka NC (2017) Psychosocial dysfunction among adolescents who abuse substances in secondary schools in Abakaliki, Nigeria. Nig J Clin Pract 20: 665669.

25. Igwe WC, Ojinnaka NC (2010) Mental health of adolescents who abuse psychoactive substances in Enugu, Nigeria- A crosssectional study. Ital J Pediatr 36: 53.

26. Jellinek MS, Murphy MJ (1986) Brief psychosocial screening in outpatient paediatric practice. J Paediatr 109: 374-378.

27. Hedderick E, Buchhaiter JR (2003) Comorbidity of childhoodonset epilepsy and psychiatric and behavioural disorders: A population-based study. Ann Neurol 54: 115.

28. Kiecott-Glacer JK, Preacher KJ, MacCallum RC, et al. (2003) Chronic stress and age-related increases in the pro-inflammatory cytokines IL-6. Proc Natl Acad Sci 100: 9090-9095.
29. Verrotti A, Moavero R, Panzarino G, et al. (2018) The challenge of pharmacotherapy in children and adolescents with epilepsyADHD comorbidity. Clin Drug Investig 38: 1-8.

30. Caplan R, Siddarth P, Gurbain S, et al. (2004) Psychopathology and paediatric complex partial seizures: seizure-related, cognitive and linguistic variables. Epilepsia 45: 1273-1281.

31. Karanja SW (2017) Prevalence of Psychosocial problems in children with epilepsy attending the child neurology clinic at Kenyatta National Hospital. University of Nairobi, Kenya.

32. Dunn DW, Austin JK (2004) Differential diagnosis and treatment of psychiatric disorders in children and adolescents with epilepsy. Epilepsy Behav 3: S10-S17.

33. Austin JK, Dunn DW, Caffrey HM, et al. (2002) Recurrent seizures and behavioural problems in children with first recognised seizures: a prospective study. Epilepsia 43: 1564-1573.

34. Nur FT, Azmi N, Hermasari BK (2020) Risk factors for behavioural problems in pediatric epilepsy. Indones J Med 5: 162-169.

35. Bragatti JA, Torres CM, Londero RG, et al. (2010) Prevalence of psychiatric comorbidities in temporal lobe epilepsy: The value of structured psychiatric interviews. Epileptic Disord 12: 283-291.

36. Asindi AA, Eyong KI (2012) Stigma on Nigerian children living with epilepsy. J Pediatr Neurol 10: 105-109.

37. Turkey A, Beavis JM, Thapar AK, et al. (2008) Psychopathology in children and adolescents with epilepsy: an investigation of predictive variables. Epilepsy Behav 12: 136-144.

38. Helal SI, Megahed HS, Samar M Salem, et al. (2013) Monotherapy versus polytherapy in epileptic adolescents. Maced J Med Sci 6: 174-177.

39. Olley BO (2004) Psychosocial and seizure factors related to depression and neurotic disorders among patients with chronic epilepsy in Nigeria. Afr J Med Sci 34: 39-44.

40. Vitera E (2012) Stigmatization of patients with epilepsy: A review of the current problem and assessment of the perceived stigma in Bulgarian patients. Epilepsy Behav 25: 239-243.

DOI: $10.36959 / 595 / 429$

Copyright: (c) 2021 Nnajekwu CO, et al. This is an open-access article distributed under the terms of the Creative Commons Attribution License, which permits unrestricted use, distribution, and reproduction in any medium, provided the original author and source are credited. 